\title{
Neonatal Mortality Due to Birth Defects
}

\author{
Tahmina Banu ${ }^{1 *}$ \\ Tasmiah Tahera Aziz ${ }^{1}$ \\ ${ }^{1}$ Chittagong Research Institute for \\ Children Surgery [CRICS] \\ Chattogram, Bangladesh
}

*Correspondence to:

\begin{tabular}{l} 
Dr. Tahmina Banu \\
Professor \\
Chittagong Research Institute for \\
Children Surgery [CRICS] \\
Chattogram, Bangladesh \\
Mobile : +88 01711720635 \\
E-mail: proftahmina@gmail.com, www.cricsbd.org \\
\hline Date of Submission : 20.07 .2019 \\
Date of Acceptance : 27.08 .2019
\end{tabular}

www.banglajol.info/index.php/CMOSHMCJ
Neonatal period, considered as the "most vulnerable time for a child's survival", is the highest death risk period. In the last three decades child mortality rate fell by 51 per cent. However, the decline in mortality has been slower in neonates than in older children ${ }^{1}$.

2.7 million Neonates die each year that accounts for $45 \%$ of deaths among children under the age of five globally ${ }^{2}$. In 1990, neonatal death accounted for $40 \%$ of total under 5-years deaths, which rose up to $47 \%$ in $2017^{3}$. According to WHO estimates in 2017 , neonatal death frequency was 7000 per day with about 1 million deaths on the first day of life. Additionally the number of neonatal deaths was close to 1 million within the next 6 days $^{3}$.

Moreover, neonatal mortality rate varies in different regions and countries with South Asia having nine times the more neonatal death risk than Higher-Income Countries (HICs). Also another frightening fact in South Asia, the proportion of neonatal deaths is among the highest $(60 \%)$ along with a relatively high under-five mortality rate ${ }^{4}$.

Sustainable Development Goal (SDG) 3.2 aims for the end of preventable neonatal deaths by 2030, with the goal of reducing neonatal mortality to at least as low as 12 per 1000 live births in every country ${ }^{5}$. However it is estimated that more than 60 countries will miss the target, majority of them being Southern Asian and subSaharan African countries ${ }^{4}$.

More than $80 \%$ of neonatal mortality in 2012 was caused by complications due to prematurity, intrapartum-related deaths (Including birth asphyxia) and neonatal infections. Also $9 \%$ of neonatal mortality was attributed to Birth Defects ${ }^{6}$.The trend didn't deviate along the years. Another estimate of 2017 revealed that the leading causes of neonatal death were prematurity, birth asphyxia \& birth trauma, sepsis and other infectious conditions followed by congenital anomalies ${ }^{7}$.

According to WHO definition congenital anomalies (Also known as birth defects) are "Structural or functional anomalies that occur during intrauterine life and can be identified prenatally, at birth, or sometimes may only be detected later in infancy ${ }^{8}$."

1 in 5 neonatal deaths are caused by birth defects. Worldwide each year the number is approximately 303000 newborns in the 4 weeks of birth. And most common birth defects that are responsible for these neonatal deaths are serious heart defects, lung defects, genetic conditions and brain conditions ${ }^{8,9}$.

Another alarming fact of congenital anomalies is that it can indirectly attribute to other causes of neonatal mortality. For instance, major birth defects increases the risk of pre-term birth, the number one cause of neonatal mortality. A population-based cohort study of the birth database of the Missouri Department of Health (1989-1997) including 678,693 singleton live births revealed that pre-term birth risk increased significantly by major birth defects. The risk varied with malformation type and was higher in case of multiple malformations ${ }^{10}$. Many birth defects directly or indirectly cause respiratory distress. Esophageal Atresia, a congenital anomaly, affects the alimentary tract and can lead to severe respiratory distress ${ }^{11}$. At birth most 
Posterior Urethral Valves (PUV) are presented as respiratory distress $^{12}$. Also congenital diaphragmatic hernia is one of the common surgical causes of respiratory distress in neonates ${ }^{13}$. These multifaceted aspects of congenital anomalies make preventive measures for it an effective step for the reduction of neonatal deaths directly or indirectly.

In the resolution WHA 63.17 of Sixty-third World Health Assembly, congenital anomalies were recognized as a significant cause of neonatal mortality. Also the resolution recognized that prevention and management of congenital anomalies are crucial for neonatal mortality reduction ${ }^{14}$.
Along with the life saving interventions like neonatal and maternal health care, access to skilled health professionals, access to water, sanitation, and hygiene etc, prevention of birth defects and providing effective care for the affected need to be realized for reducing preventable neonatal deaths.

Promoting and executing primary preventions, effective and early detections of congenital anomalies; immediate referral to proper facilities, building team of skilled healthcare professionals specialized in birth defects and awareness building among general populace are some of the hurdles to pass in this endeavor.

\section{REFERENCES}

1. UNICEF. Neonatal mortality. March 2018. Accessed from: https://data.unicef.org/topic/child-survival/neonatal-mortality/, Access Date: 24th July 2019.

2. World Health Organization. The Every Newborn Action Plan. Accessed from:https://www.who.int/maternal_child_adolescent/newborns/every-newborn/en/, Access Date: 24 ${ }^{\text {th }}$ July 2019

3. World Health Organization. Newborns: reducing mortality. September 2018. Accessed from:, https://www.who.int/news-room/factsheets/detail/newborns-reducing-mortality, Access Date: 24th July 2019

4. United Nations Inter-agency Group for Child Mortality Estimation (UN IGME) 'Levels \& Trends in Child Mortality: Report 2018, Estimates developed by the United Nations Inter-agency Group for Child Mortality Estimation', United Nations Children's Fund, New York, 2018.

5. World Health Organization. Sustainable Development Goal 3: Health. Accessed from:, https://www.who.int/topics/sustainable-developmentgoals/targets/en/, Access Date: 24th July 2019.

6. WHO, UNICEF. 2014. Every Newborn: an action plan to end preventable deaths. Geneva: World Health Organization. Accessed from: https://www.who.int/maternal_child_adolescent/documents/every-newborn-action-plan/en/, Access Date: 24th July 2019.

7. World Health Organization. Global Health Observatory (GHO) data. Causes of child mortality, 2017. Accessed from: https://www.who.int/gho/child_health/mortality/causes/en/, Access Date: 27th July 2019.

8. World Health Organization. Congenital anomalies, September 2016. Accessed from: https://www.who.int/en/news-room/factsheets/detail/congenital-anomalies, Access Date: 24th July 2019.

9. March of Dimes. NEONATAL DEATH. October 2017. Accessed from: https://www.marchofdimes.org/complications/neonatal-death.aspx, Access Date: 27th July 2019.

10. Purisch SE, DeFranco EA, Muglia LJ et al. Preterm birth in pregnancies complicated by major congenital malformations: A population-based study. Am J ObstetGynecol 2008;199:287.e1-287.e8.

11. Pinheiro PF, Simões e Silva AC, Pereira RM. Current knowledge on esophageal atresia. World J Gastroenterol. 2012;18(28):3662-3672.

12. Perks AE, MacNeily AE, Blair GK. Posterior urethral valves. J Pediatr Surg. 2002;37(7):1105-1107.

13. Kumar A, Bhatnagar V. Respiratory distress in neonates. Indian J Pediatr. 2005;72(5):425-428

14. Resolution WHA63.17. Birth defects. 2010. Accessed from: http://apps.who.int/gb/ebwha/pdf_files/WHA 63/A63_R17-en.pdf, Access Date: 27th July 2019. 